\title{
Students' perception of reactions towards disruptive behaviour in Norwegian and American schools.
}

\author{
Liv Duesund and Magnar Ødegård \\ Department of Special Needs Education, University of Oslo, Norway \\ Department of Sociology, University of California, Berkeley USA
}

\begin{abstract}
Findings from this comparative study include students' perceived experience on the disruptive behaviour during class by utilizing a questionnaire administered in Norwegian and American schools. The sample in the study is 1153 students between $15-17$ years old. We present the student perspective of how students and teachers react towards disruptive behaviour. In both countries, reactions from students indicated a tendency to escalate disruptive behaviour, while the reactions from teachers mostly decreased disruptive behaviour. We analyse these findings in light of the concept of emotional involvement.
\end{abstract}

\section{Introduction}

During school class sessions, students are exposed to a variety of tasks in rapidly shifting different fields. Each task demands a set of skills they needed to acquire in order to improve their academic and social skills. They need skills to cope with their thoughts and emotions to flexibly engage in the many activities, social settings, perceptions of justice and conflicts between their own interests and others'.

The study presented in this article is part of the project "A Comparative Study of Disruptive Behaviour between Schools in Norway and the United States" and is a collaboration between Norwegian and American researchers. The aim of the research was to 
assess students' perceptions of and reactions to disruptive behaviour. Included in the assessments were the reactions students and teachers display when disruptive behaviour occurs and what occurs after these reactions. We examined the following:

\section{(1) How do teachers and students react to disruptive behaviour?}

(2) How do the reactions of teachers and students influence the students who are disruptive in class?

Before addressing these questions, we outline our operationalization of disruptive behaviour in schools. Furthermore, we discuss the concepts of classroom-climate, skills and emotional involvement and responsibility related to our findings. These terms create the foundation for the discussion of our results.

\section{Disruptive behaviour}

There is wide agreement among researchers that disruptive behaviour is one of the biggest challenges in schools as well as one of the main concerns and sources of stress for both students and teachers (Nash, Schlösser, and Scarr 2016; Greene 2014; Duesund 2014; Levin and Nolan 2010; Colvin 2010). Disruptive behaviour is often attributed to individual and/or environmental features (Befring and Duesund 2012). Such behaviour can occur when demands from adults conflict with the students' own perceptions of a situation, and disruptive behaviour causes considerable frustration for both students and teachers (Woltering and Qinxin 2016). Our focus is on processes of social relationships within classrooms. In this context, we find demands for student-achievement related to their subjects as well as studentinteraction with peers and teachers. We define disruptive behaviour in classrooms as:

"Any behaviour that is perceived as sufficiently off-task in the classroom, as to distract the teachers and/or class-peers from learning activities". 


\section{Reactions to disruptive behaviour}

A large body of research on successful teaching seems to be based on rationalist views, meaning that practitioners are in possession of a 'stock' of practical knowledge that could be consistently applied in a variety of contexts (Gottlieb 2015). This involves a way of thinking entailing beliefs that teachers are able to develop a set of rules based on years of teaching experience. This enables them to establish an arsenal of strategies that they can apply when facing different challenges in the classroom (Gottlieb 2015). We regard reactions to disruptive behaviour as an effort to cope with such challenges in the classroom. Our assumption is that disruptive behaviour is a phenomenon that stimulates reactions from students and teachers. Such reactions might be asking the ones that are being disruptive to be quiet, or wilfully ignoring the disruptive behaviour by not displaying an observable reaction. Due to the immediate demands of classrooms, it is not always possible to apply rules and principles when faced with disruptive behaviour as presented by the rationalist perspective. Disruptive behaviour often causes frustration, and impairs the ability of students and teachers possess to provide a contemplated response they are certain will provide a desired effect (Ødegård 2014; Dreyfus and Wrathall 2007). In contrast to the rationalist perspective, our focus presumes that reactions are not necessarily readily available in a 'toolbox' created on the basis of earlier experiences with disruptive behaviour. As such, we regard reactions as part of pre-reflective and immediate human interactions and not only involving reflection and 'correct' choice of action towards a challenging situation. We focus on any possible reactions that might occur and their influence on disruptive students as they reported by the students. Based on these rationales, we define reactions towards disruptive behaviour as:

"Any explicit reaction directed towards disruptive behaviour when it occurs during class". 


\section{The classroom climate}

Schools are not just an arena for academic learning, but also one of the main arenas where students interact with peers and adults (Bauman 2008; Bauman and Mazzeo 2012; Putnam 2000). Concepts that apply to the academic and social climate in class include learning environment, classroom environment, and classroom climate (Postholm 2013; Filsecker and Hickey 2014; Ratcliff et al. 2010). The classroom climate includes issues that promote or hinder academic, social, and emotional learning (Evertson and Weinstein 2006). Within the literature about the classroom climate, we find consideration of teachers' abilities to prevent disruptive behaviour and promote academic, social and emotional growth. A positive classroom climate may be seen as a classroom with a low degree of disruptive behaviour, where the teacher has control, the students respect each other and that promote good learning conditions.

Previous research has outlined a set of rules and principles for establishing a positive classroom climate, with some examples being: (1) maximize structure and predictability, engage students and (2) use a continuum of strategies to reward positive behaviour and react to inappropriate behaviour (Jacobsen and Thorsvik 1997; Overland 2007; Simonsen et al. 2008).

The focus of our research was on reactions to inappropriate behaviours in classrooms. According to Payne (2015), rewards and sanctions towards disruptive behaviour often lean on behaviourist principles. When sanctions are used as a reaction to disruptive behaviour, students often view them as unfair as the students are not treated as active agents (Kauffman et al. 2010; Leflot et al. 2010; Greene 2014; Clunies-Ross, Little, and Kienhuis 2008). Examples of such reactions are teachers yelling, excluding disruptive students form classrooms, detention and commanding students to be quiet. When students perceive sanctions as unfair, they might lose interest in the tasks at hand, perceive teachers negatively, 
with well-being possibly decreasing and disruptive behaviour intensifying (Colvin 2010;

Greene 2014; Honkasilta, Vehmas, and Vehkakoski 2016; Nash, Schlösser, and Scarr 2016; Payne 2015). The unwanted consequences of teacher-reactions towards disruptive behaviour could raise the following questions: (a) whether teachers know about, or follow, the rules and principles that have been provided as ways of dealing with disruptive behaviors, or (b) whether the rules and principles are not suitable to cover the complexity and dynamism of classrooms. An answer to (a) could be that there should be a closer connection between research and practice, as has been advocated by the Norwegian Ministry of Education and Research (2008), claiming that many teachers are in need of more tools to meet challenges in classrooms. Following up on this, reflections on (b) are also needed. Managing disruptive behaviour is not like fixing a car. It also includes emotions, feeling of frustrations and burnout, laying forth demands of intuitive and immediate action from both teachers and students.

\section{Skill acquisition and emotional involvement}

Teachers and students need a wide set of skills when interacting in classrooms, such as to manage disruptive behaviour, establish a positive classroom climate, as well as focusing on tasks provided. To address the concept of skills relevant to these areas, we utilize the skillmodel of Dreyfus and Dreyfus (1986) as the foundation of our research and discussion. The skill model was developed as a critique of technological rationality and detached observation and reflection. The model illustrates a movement from reliance on abstract principles to use of past concrete experience, as well as a passage from detached observer to involved performer in a situation (Duesund and Jespersen 2004, 226). Dreyfus and Dreyfus proposed the following five stages in their skill model: (1) novice, (2) advanced beginner, (3) competence, (4) proficiency, and (5) expertise. The five stages illustrate how people go from following simple rules (novice) to intuitively performing activities with a high degree of success (expert) (Dreyfus and Dreyfus 2014; Dreyfus and Dreyfus 1986). Our focus in the skill model is based 
on the concept of emotional involvement, which is a prerequisite for development of the skills described in the model. This is not necessarily a part of the 'stock of practical knowledge' implied by the rationalist principles cited above. This stands in contrast to detached and rulefollowing practice without the agent feeling emotionally involved in his or her actions (Dreyfus 2014).

One perspective on successful teacher practice is seeing it as a result of gathering experiences and creating rules for action that are applicable in many situations (Gottlieb 2015). In the context of disruptive behaviours this could involve teachers gaining experience with different situations where disruptive behaviour occurs (and different kinds of disruptive behaviour), and creating rules for action to successfully manage these kinds of behaviours in the future. Rules for the development of a classroom climate promoting learning involve factors like establishing structure, positive reinforcement and motivating students.

Classrooms and student behaviours are very diverse and often unpredictable. Rules and maxims may not always be sufficient. The approach of Hubert and Stuart Dreyfus (1986) begins with a dependence on rules and maxims on a level of novice and advanced beginner. At the level of expertise, the actions of the teacher involve an overview of situations and successful application of intuition when encountering challenging tasks in the classroom (Benner 2004; Dreyfus and Dreyfus 1986; Gottlieb 2015). Teachers possess skills within didactics, within subjects and in relation to students. Meanwhile, disruptive behaviour may cause teachers to feel:

“de-skilled, disheartened and stressed" (Geddes 2006, 2)

Being de-skilled means disruptive behaviour affects all aspects of teachers' work in the sense that they are no longer able to use their existing pedagogical and didactical skills to facilitate learning for their students. They might perceive that the rules and principles they have 
gathered through experience no longer work due to the many forms disruptive behaviour can take (Ødegård 2014; Dreyfus and Dreyfus 1986). If teachers are disheartened it could lead them to become emotionally detached from their practice and resigned when facing disruptive behaviour. According to Dreyfus' model of skill-acquisition, this occurs at the level of competence. A competent performer knows rules and maxims for actions and is able to recognize an overwhelming number of possibly relevant procedures and elements in a situation. This creates uncertainty, as the performer needs to decide what to do without knowing the outcome. This means that the performer could become emotionally detached from the situation. Such detachment occurs when the performer decides to cope with a situation by putting the responsibility on other practitioners or feel that he or she has not been taught the appropriate rules for action (Dreyfus 2004b). For teachers, this could involve becoming emotionally detached from the situation in the sense that they do not provide an observable action, become emotionally distressed, and may place the blame on a lack of knowledge provided. When this occurs, the disruptive behaviour will continue and could even escalate as the students are left alone to manage it (Ødegård 2014). A key concept at the level of competence is responsibility. To improve a skill within a domain, actors need to take responsibility and become emotionally involved in their actions, regardless of the outcomes or potential outcomes. Dreyfus $(2004 b, 179)$ elaborates:

“What matters is taking responsibility for one's successful and unsuccessful choices, even brooding over them - not just feeling good or bad about winning or losing, but replaying one's performance in one's mind step by step".

Teachers who do not take responsibility for their actions are severely hindered from becoming more skilled in their practice as emotional involvement is a necessity for this to happen (Dreyfus and Wrathall 2014; Gottlieb 2015). Students also need a wide array of skills to be successful in school and may become disheartened. Their disruptive behaviour could also be a 
way of refusing to become emotionally involved and a way of 'escaping' the demands of schools as students are in situations where they need to act without knowing the outcome of their actions (e.g. when they are working on a challenging task that they do not yet fully grasp). The students may become disruptive instead of embarking on a challenging task that they could fail (Ødegård 2014; Dreyfus and Dreyfus 1986).

\section{Methods}

The following illustrates the methodology of our study, including an overview of the study, participants, research design, development of research instrument and analysis of data.

\section{Overview}

We used a questionnaire that began by asking students if other students had disturbed them during the last week. The aim of this question was to examine the ways disruptive behaviour could be regarded as part of the everyday lives of students in schools, meaning whether it could be experienced as a phenomenon that they are familiar with and which has occurred. In the questionnaire, we also posed questions about how students react towards disruptive behaviour. Doing so, we aimed to collect data related to how students perceive their own influence in classrooms. The results could provide us with indications of how students perceive their own (and other students') influence on disruptive behaviour in the classroom. Categories related to these questions in the questionnaire are whether students' reactions could influence other students in the sense that they get more disruptive, or if the disruptive behaviour decreases. Such findings could be seen in light of students perceiving that their influence matters in the classroom. Finally, we asked students about their perception of teachers' reactions. We wanted to get indications of how students perceive the teachers' influence on disruptive behaviour. As teachers are the main authority in the classroom responsible for managing disruptive behaviour, we wanted to examine how the teachers' 
reactions to disruptive behaviour influenced disruptive students in the direction of getting quiet, or if their disruptive behaviour intensified. The Norwegian Centre for Research Data and the Institutional Review Board at the American university, where we are affiliated, evaluated ethical aspects of our research and gave their approval.

\section{Participants}

The sample in the study consists of 1153 students, with 609 (52.8\%) being American and 544 (47.2\%) from Norway. The participants were of the ages 15-17 years. Out of the 609 American students, 318 (overall, 27.6\%) were female and 291 (overall, 25.2\%) male. The 544 Norwegian students consisted of 252 (overall, 21.9\%) females and 292 (overall, 25.3\%) males.

Our data were collected in a city in the eastern part of Norway and in the west coast of the US.

\section{Research design}

The design of our study includes one qualitative and one quantitative strain, divided into four phases. These are (1) designing the qualitative strand and data collection, (2) analysing data from the qualitative strand and developing the questionnaire, (3) implementation of questionnaire and quantitative data collection, and (4) analysing data from the questionnaire.

Phases 1 and 2 were qualitative and included observational studies identifying categories of disruptive behaviour conducted by master's students at the University of Oslo. Data from these studies were utilized to create categories in the development of the questionnaire implemented in the quantitative strand. We will not report the qualitative data to a great extent, except in the next section about the questionnaire-development.

\section{Developing the questionnaire}

Our questionnaire consisted of 23 items, with 16 measured on a nominal level and seven at an ordinal level. The questionnaire (appendix 1) addressed three themes, being (1) degree of 
disturbance, (2) displayed disruptive behaviour, and (3) reactions to disruptive behaviour (which is the focus of this article).

\section{Implementation of the questionnaire and quantitative data collection}

To validate the questionnaire, three pilot studies were conducted and discussed with members of the research group ${ }^{1}$. Administration of two pilot studies was done in Norway, and one in the US. The questionnaire was implemented in paper-and-pencil format inside classrooms. One researcher was present at all times to oversee the procedure. The students received both verbal and textual instructions on how to answer the questionnaire. We presented the questionnaire in the native language in both countries (Norwegian and English).

\section{Analysis of data}

All 23 items in the questionnaire have response rates above $95 \%$, which means that there is a very low likelihood that missing data will distort the findings (Fowler 2013). Based on this rationale, missing data are not part of our analysis. Our analytical approach is in line with what (Johnson and Christensen 2014) presents as the goal of descriptive statistics, which is to summarize or make sense of a dataset. We conducted homogeneity analysis and tests of two proportions to calculate statistically significant differences and commonalities between Norwegian and American students in the sample.

\section{Results}

The results from our questionnaire are provided in tables with a brief summary of core findings in each table. Indications of statistically significant differences are presented in notes under each table, as well as which statistical procedures were used. Note that we only compare American and Norwegian students, and do not compare groups within the countries. When we refer to 'all students', 'male students' and 'female students', we are addressing the comparisons between the students in each country and not within. 


\section{Disruptive behaviour during the last week of being surveyed}

Table $1^{2}$ shows whether students had been disturbed or disturbed others during the last week of being surveyed. The table shows that most students in both Norway and the US said that disruptive behaviour disturbed them during the last week of being surveyed. Most students reported disturbances during the last week of being surveyed.

Table 1: Disruptive behaviour during the last week of being surveyed

\begin{tabular}{|c|c|c|c|c|c|c|c|}
\hline \multicolumn{8}{|c|}{ Disruptive behaviour displayed by other students } \\
\hline & \multicolumn{3}{|c|}{ American students $(\%)$} & \multicolumn{3}{|c|}{ Norwegian students $(\%)$} & \multirow[b]{2}{*}{ Total } \\
\hline & All & Female & Male & All & Female & Male & \\
\hline Yes & 65.6 & 69.6 & 61.1 & 57.8 & 65.2 & 51.4 & 61.9 \\
\hline No & 34.4 & 30.4 & 38.9 & 42.2 & 34.8 & 48.6 & 38.1 \\
\hline $\mathrm{N}$ & 598 & 313 & 285 & 538 & 250 & 288 & 1136 \\
\hline
\end{tabular}

NOTE: statistically significant differences between all the American and Norwegian students $(\mathrm{p}=.007)$, American and Norwegian males ( $\mathrm{p}=.020)$, but not between American and Norwegian females $(\mathrm{p}=.262)$. Statistical tests: Chi-square test of two proportions. 


\section{Student-reactions towards disruptive behaviour}

Table 2 shows the most frequent student reactions towards disruptive behaviour. Panel A

illustrates how students perceive the reactions of other students when someone is being

disruptive in class. Panel B shows the self-reported own reactions to disruptive behaviour.

The most frequent student-reaction students report to be done by others (Panel A) is either

'also get disruptive' or 'nothing'. In Panel B, students describe their own reactions and

'nothing' clearly dominates the data.

Table 2: Student reactions towards disruptive behaviour

\begin{tabular}{|c|c|c|c|c|c|c|c|}
\hline \multirow[t]{3}{*}{ Panel A: Reactions of others } & \multirow{2}{*}{\multicolumn{3}{|c|}{ American students }} & \multirow{2}{*}{\multicolumn{3}{|c|}{ Norwegian students }} & \multirow[b]{3}{*}{ Total } \\
\hline & & & & & & & \\
\hline & All & Female & Male & All & Female & Male & \\
\hline Telling teacher & 0.5 & 0.3 & 0.7 & 4.0 & 2.8 & 5.1 & 2.1 \\
\hline Ask them to be quiet & 11.1 & 11.4 & 10.7 & 11.1 & 9.7 & 12.3 & 11.1 \\
\hline Raising of voice, telling them to be quiet & 20.0 & 19.9 & 20.1 & 20.8 & 22.7 & 19.2 & 20.4 \\
\hline Nothing & 29.9 & 26.2 & 33.9 & 13.2 & 10.9 & 15.2 & 22.1 \\
\hline Also get disruptive & 38.6 & 42.3 & 34.6 & 50.9 & 53.8 & 48.2 & 44.3 \\
\hline $\mathrm{N}$ & 606 & 317 & 289 & 523 & 247 & 276 & 1129 \\
\hline \multicolumn{8}{|l|}{ Panel B: Own reactions } \\
\hline & \multicolumn{3}{|c|}{ American students } & \multicolumn{3}{|c|}{ Norwegian students } & \\
\hline Own reactions & All & Female & Male & All & Female & Male & Total \\
\hline Telling the teacher & 0.7 & 0.9 & 0.3 & 3.6 & 4.1 & 3.2 & 2.0 \\
\hline Raising of voice, telling them to be quiet & 7.1 & 6.9 & 7.3 & 11.9 & 11.4 & 12.3 & 9.3 \\
\hline Also get disruptive & 10.4 & 9.7 & 11.1 & 24.7 & 21.6 & 27.4 & 17.0 \\
\hline Ask them to be quiet & 19.4 & 20.1 & 18.7 & 18.2 & 24.5 & 12.6 & 18.9 \\
\hline Nothing & 62.4 & 62.3 & 62.6 & 41.6 & 38.4 & 44.4 & 52.8 \\
\hline $\mathrm{N}$ & 607 & 318 & 289 & 522 & 245 & 277 & 1129 \\
\hline
\end{tabular}

NOTES:

Panel A: Statistically significant differences are found between all the American and Norwegian students $(p=.000)$ within the categories "also get disruptive", "telling the teacher" and "nothing". Such differences are also found amongst the male and female students within the same categories.

Panel B: Statistically significant differences are found between all students within the categories "also get disruptive", "raising of voice, telling them to be quiet", "telling the teacher" and "nothing". Similar differences are found for female students within the same categories except "raising of voice, telling them to be quiet". For the male students, statistically significant differences were found within all categories.

Statistical tests: Homogeneity analysis, z-test with Bonferroni correction. 


\section{Influence of student-reactions towards disruptive behaviour}

Table 3 shows the perceived influence of student-reactions towards disruptive behaviour.

Panel A presents the percentages of how students perceive influence of the reaction of other students. Panel B describes percentages of how students perceive influence of their own reactions. When students report the influence of other students' reactions, they mainly report that 'nothing happens'. This is also the case when students report the influence of their own reactions.

Table 3: Influence of student-reactions towards disruptive behaviour

Panel A: Influence of other students' reactions towards disruptive students

\begin{tabular}{|c|c|c|c|c|c|c|c|}
\hline \multirow[t]{2}{*}{ 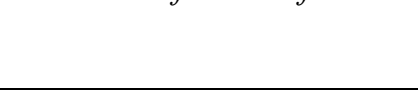 } & \multicolumn{3}{|c|}{ American students } & \multicolumn{3}{|c|}{ Norwegian students } & \multirow[b]{2}{*}{ Total } \\
\hline & All & Female & Male & All & Female & Male & \\
\hline They get quiet & 3.9 & 3.5 & 4.3 & 5.1 & 3.3 & 6.6 & 4.4 \\
\hline They become less disruptive & 20.1 & 20.6 & 19.5 & 26.9 & 26.0 & 27.7 & 23.2 \\
\hline They get more disruptive & 25.6 & 25.7 & 25.5 & 24.4 & 21.9 & 26.6 & 25.0 \\
\hline Nothing happens & 50.4 & 50.2 & 50.7 & 43.7 & 48.8 & 39.1 & 47.3 \\
\hline $\mathrm{N}$ & 597 & 315 & 282 & 513 & 242 & 271 & 1110 \\
\hline
\end{tabular}

Panel B: Influence of own reactions towards disruptive students

\begin{tabular}{|c|c|c|c|c|c|c|c|}
\hline & \multicolumn{3}{|c|}{ American students } & \multicolumn{3}{|c|}{ Norwegian students } & \multirow[b]{2}{*}{ Total } \\
\hline & All & Female & Male & All & Female & Male & \\
\hline They get more disruptive & 7.8 & 6.5 & 9.3 & 9.3 & 10.0 & 8.7 & 8.5 \\
\hline They get quiet & 8.1 & 6.8 & 9.6 & 11.1 & 7.4 & 14.4 & 9.5 \\
\hline They become less disruptive & 15.6 & 15.9 & 15.3 & 23.0 & 23.8 & 22.3 & 19.0 \\
\hline Nothing happens & 68.4 & 70.8 & 65.8 & 56.6 & 58.9 & 54.5 & 63.0 \\
\hline $\mathrm{N}$ & 589 & 308 & 281 & 495 & 231 & 264 & 1084 \\
\hline
\end{tabular}

NOTES: Panel A: statistically significant between all students $(\mathrm{p}=.026)$ and male students $(\mathrm{p}=.023)$ within the categories "they become less disruptive" and "nothing happens". Panel B: statistically significant differences between all students $(p=.001)$, female students $(p=.027)$ and male students $(p=.027)$ within the categories "they become less disruptive" and "nothing happens" for all students as well as male and female.

Statistical tests: Homogeneity analysis, chi-square test of two proportions. 


\section{Students' perception of teacher-reactions towards disruptive behaviour}

Table 4 shows students' perception of teacher-reactions towards disruptive behaviour. Most students report that teachers either react to disruptive behaviour by 'ask them to be quiet' or 'raise their voice and tell them to be quiet'.

Table 4: Students' perception of teacher-reactions towards disruptive behaviour

\begin{tabular}{|c|c|c|c|c|c|c|c|}
\hline \multicolumn{8}{|l|}{ Teacher reactions towards disruptive behaviour } \\
\hline & \multicolumn{3}{|c|}{ American students } & \multicolumn{3}{|c|}{ Norwegian students } & \multirow[b]{2}{*}{ Tota } \\
\hline & All & Female & Male & All & Female & Male & \\
\hline Call their parents & 0.2 & 0.3 & 0.0 & 1.2 & 1.3 & 1.1 & 0.6 \\
\hline Nothing & 2.7 & 2.6 & 2.8 & 3.8 & 3.0 & 4.4 & 3.2 \\
\hline Exclude them from class & 2.3 & 2.6 & 2.1 & 7.5 & 7.2 & 7.8 & 4.7 \\
\hline Look at them in a strict way & 5.8 & 6.7 & 4.9 & 6.3 & 9.4 & 3.7 & 6.1 \\
\hline Walk over to them and ask them to be quiet & 8.0 & 8.6 & 7.3 & 5.9 & 3.8 & 7.8 & 7.1 \\
\hline Walk over to them and tell them to be quiet & 11.4 & 11.5 & 11.2 & 12.9 & 11.1 & 14.4 & 12.0 \\
\hline Raise their voice and tell them to be quiet & 28.0 & 28.1 & 28.0 & 45.7 & 46.8 & 44.8 & 36.1 \\
\hline Ask them if they could be quiet & 41.6 & 39.6 & 43.7 & 16.6 & 17.4 & 15.9 & 30.2 \\
\hline $\mathrm{N}$ & 599 & 313 & 286 & 505 & 235 & 270 & 1104 \\
\hline
\end{tabular}

NOTES: Statistically significant differences are found within "raise their voice and tell them to be quiet" and ask them if they could be quiet" between all students, male and female $(\mathrm{p}=.000)$.

Statistical tests: Homogeneity analysis, chi-square test of two proportions, Fisher's exact test. 


\section{Influence of teacher-reactions towards disruptive behaviour}

Table 5 shows the perceived influence of the two dominating teacher-reactions. Panel A shows the percentages within 'ask them to be quiet' and Panel B percentages within 'raise their voice and tell them to be quiet' and 'ask them to be quiet'. The rationale behind this analysis is that those categories heavily dominate the teacher-reactions (Table 3), and because the difference between them is statistically significant between American and Norwegian students. However, within both categories in each country, most students report that the influence of 'raise their voice and tell them to be quiet' and 'ask them to be quiet' either involves the disruptive students to 'become less disruptive' or 'get quiet'. As these results were highly similar in both countries, we also ran an analysis examining how any teacherreaction influenced disruptive students. The findings were similar, with 'become less disruptive' or 'get quiet' most frequent also in this case.

Table 5: Influence of asking or telling disruptive students to be quiet

\begin{tabular}{|c|c|c|c|c|c|c|c|}
\hline \multicolumn{8}{|c|}{ Panel A: Influence of teachers asking students who are disruptive in class to be quiet } \\
\hline & \multicolumn{3}{|c|}{ American students } & \multicolumn{3}{|c|}{ Norwegian students } & \multirow[b]{2}{*}{ Total } \\
\hline & All & Female & Male & All & Female & Male & \\
\hline They get more disruptive & 1.2 & 1.6 & 0.8 & 4.8 & 4.9 & 4.7 & 2.1 \\
\hline Nothing happens & 12.6 & 13.8 & 11.3 & 11.9 & 14.6 & 9.3 & 12.4 \\
\hline They get quiet & 32.8 & 26.8 & 38.7 & 31.0 & 17.1 & 44.2 & 32.3 \\
\hline They become less disruptive & 53.4 & 57.7 & 49.2 & 52.4 & 63.4 & 41.9 & 53.2 \\
\hline $\mathrm{N}$ & 247 & 123 & 124 & 84 & 41 & 43 & 331 \\
\hline \multicolumn{8}{|c|}{ Panel B: Influence of teachers raising their voice towards students who are disruptive in class } \\
\hline & \multicolumn{3}{|c|}{ American students } & \multicolumn{3}{|c|}{ Norwegian students } & \\
\hline & All & Female & Male & All & Female & Male & Total \\
\hline They get more disruptive & 2.4 & 3.4 & 1.3 & 2.2 & 2.8 & 1.7 & 2.3 \\
\hline Nothing happens & 9.5 & 8.0 & 11.3 & 11.6 & 9.3 & 13.6 & 10.7 \\
\hline They get quiet & 31.5 & 27.3 & 36.3 & 25.3 & 23.4 & 27.1 & 28.0 \\
\hline They become less disruptive & 56.5 & 61.4 & 51.2 & 60.9 & 64.5 & 57.6 & 59.0 \\
\hline $\mathrm{N}$ & 168 & 88 & 80 & 225 & 107 & 118 & 393 \\
\hline
\end{tabular}

NOTES: There are no statistically significant differences in this table.

Statistical tests: Homogeneity analysis 


\section{Discussion}

In the following, we will discuss disruptive behaviour as an everyday phenomenon and in light of the concept of emotional involvement.

\section{Disruptive behaviour as an everyday phenomenon}

Table 1 reported the percentages of students who stated whether they had been disturbed during the past week. Our aim was to study the everyday lives of the students in schools during class, by asking about their perception of what is going on when disruptive behaviour occurs. The everyday we refer to is characterized by shared public actions (Dreyfus 2004a). Such actions are holding a conversation or attending class. Due to the high frequency of disruptive behaviour reported by the students in our sample, disruptive behaviour seems to be part of everyday lives in schools. Earlier findings from our research endorse this, with most students reporting to have been disturbed on a weekly, and often daily, basis. Further, coping with everyday phenomena requires a set of skills (Dreyfus and Dreyfus 1986). In schools, such skills allow students and teachers to interact with each other and create an environment that promotes learning (König and Kramer 2016; Postholm 2013). In other words, experiencing to be de-skilled as a cause of disruptive behaviour could occur every day for both students and teachers alike.

Disruptive behaviour stands in the way of establishing a classroom climate that promotes learning and well-being. Qualitative studies within the current research project conducted by master's students at the University of Oslo between 2011 and 2014 seem to support this, with each describing that disruptive behaviour affects both the classroom climate and the individual student (Ødegård 2011; Stavnes 2013; Solberg 2013; Valseth 2013; Fossum 2011). 


\section{Student involvement and classroom climate}

In this section, we discuss findings related to the reactions towards disruptive behaviour reported by the students in our sample, presented in table 2, 3, 4 and 5 .

\section{Students' reactions to disruptive behaviour}

Asking questions about which kinds of reactions students display towards disruptive behaviour allows us to obtain indications of their perceived influence on such behaviour when it occurs. The importance of asking this question was underlined by Pintrich and Schunk (2002) who pointed out that students having control and autonomy in the classroom can be beneficial for both their motivation and the promotion of a positive classroom climate. It has also been documented that student involvement when issues in the classroom occur can play a part in decreasing the frequency of disruptive behaviour (Greene 2014). A high degree of disruptive behaviour severely damages the quality of social and academic activities in schools. Our findings indicate that students perceive other students as displaying an observable reaction more often when disruptive behaviour occurs. When asking students how they themselves react, they mainly answer they do not. They may perceive that they have little influence on the behaviour of others. One could also claim that students do not possess the necessary skills to manage disruptive behaviour themselves. If they do, they could be afraid to use them, as they do not know the outcomes. Students are not able to sufficiently cope with what is occurring within the classroom or do not have the confidence to embark on such a challenge. Another possibility is that students cope with disruptive behaviour by not displaying an observable reaction and purposefully try to "ignore" this behaviour.

A large proportion of students report that other students 'also get disruptive', indicating that students perceive that disruptive behaviour spreads across the classroom when it occurs (see Table 3, Panel A). In other words, disruptive behaviour seems to be contagious. Norwegian students seem to be more likely to also become disruptive when someone is being 
disruptive in class than are the American students. This indicates that the American students perceive disruptive behaviour to be less contagious than do the Norwegians. The students in the US were encouraged to be verbally active during class and ask questions, which is part of their grading system. Norwegian students also might be rewarded for this, but it does not seem to be part of the grading system known to the students. They did not seem to be equally encouraged to engage in verbal activity in class and they are not receiving continuous updates on their grades as we observed in the US. This may have an impact in that other criteria are included as being disruptive in Norway than in the US.

Also getting disruptive can be regarded as a way of coping with disruptive behaviour. When the disruptions occur, the students might spontaneously react to them by imitating the behaviour of others. This is not necessarily something that they do intentionally or to break the rules in the classroom, but something that happens without reflection. This can be understood in light of Dreyfus (2004a) claims that human behaviour can spread and create a 'common-behaviour' where members of a group behave in the same way as they are influenced by each other. In other words, disruptive behaviour becomes a shared and everyday activity.

A classroom climate that promotes learning should not be viewed only as a responsibility of teachers, with students as passive bystanders. Assuming responsibility of ones actions increases emotional involvement in tasks one is doing and it is also closely connected to developing skills within any domain (Dreyfus and Dreyfus 1986).

The proportions in Table 3 within the category 'telling the teacher' are very low in both countries. This indicates an aversion by students to notify the teacher when they perceive that someone is being disruptive. Classrooms are settings with a large amount of social comparisons and students might not be willing to 'tattle-tale' on their peers, at least not in the moment disruptive behaviour occurs. Some students commented, 'It is the teachers job' to 
make sure that students stop being disruptive in class, and that their reactions do not matter. This could be regarded as an interesting comment as some students perceive that it is the teachers' job to react towards disruptive behaviour, but students do not seem to explicitly put this responsibility on the teachers by notifying them that other students are disturbing them. The issue here is that the responsibility of creating a positive classroom climate should not be the sole responsibility of the teachers, but a collaborative effort together with students. This collaborative effort may be something that needs to be learned both by teachers and students.

Teachers' collaborations with students touch upon the issue of student involvement. In many cases, teachers present students a set of rules that they are to agree upon, but they do not collaborate on creating them (Greene 2014). The idea is that students ${ }^{3}$ are capable of much more than just choosing from a set of rules for 'appropriate' classroom-behaviour. Furthermore, students should be viewed as capable of taking care of each other and establishing mutual respect and understanding both amongst themselves, but also in relation to the teachers about what kinds of behaviour are acceptable and what kinds of classroom climate they want to establish (Greene 2014; Murphy 2013).

\section{Influence of students' reactions to disruptive behaviour}

When it comes to disruptive behaviour in school, we should not exclude individual responsibilities or cultural contexts. Schools are addressing individual responsibility when it comes to learning, and they could also do the same when it comes to the students' behaviour. On the other hand, the students deserve to know about the ethical aspects of being disruptive and it includes a negative influence on their classmates as well as the learning climate (Nucci and Turiel 2009). Based on this reasoning, students should be enabled to have their voices heard in the classroom and perceive that they have actual influence on the events that are occurring. Table 4 illustrates that students' reactions towards disruptive behaviour seem to yield little influence on the students that are being disruptive in class. However, the students 
in our sample seem to have a greater belief that other students than themselves are capable of influencing students when they are disruptive in class in either a positive or negative direction. The findings in Table 4 can be applied to further illustrate a lack of student involvement (as reported by the students) when disruptive behaviour occurs. If the classroom is a setting where everyone is equal and every opinion should be valued, it might be of value that students cooperate with each other and the teacher to decrease disruptive behaviour. As mentioned in the discussion related to findings in Table 2, teachers cannot be expected to manage disruptive behaviour by themselves. One direction of assisting teachers might be to enable students to have actual influence in the classroom when disruptive behaviour occurs. This goes beyond the literature on classroom-management, indicating that students should be taken into account when creating rules and norms in the classroom. Rules and norms in the classroom are often presented by the teacher for students to discuss and not necessarily something they come up with on their own.

A set of rules for behaviour is not sufficient in order to decrease unwanted behaviour. To do so, students need to be emotionally involved in establishing a positive classroom climate (Dreyfus 2004b; Dreyfus and Wrathall 2014). Students need to perceive that their influence matters in the classroom-context. As schools play a major part in everyday lives of students it might be a good idea to more strongly emphasize academic achievement and social well-being as circular phenomena where one is dependent on the other and of equal importance.

\section{Teacher reactions and their influence on disruptive students}

Our findings indicate that it does not necessarily matter how teachers react to disruptive behaviour, as long as there is some observable reaction. The majority of students reported that disruptive students 'become less disruptive' when the teacher provided an observable reaction to the behaviour. By becoming less disruptive, the students do not completely stop their 
disruptive behaviour, but it decreases. Clunies-Ross, Little, and Kienhuis (2008) provide results that teachers have great confidence in their own ability to manage disruptive behaviour. Based on our findings, one could ask if this confidence is misplaced. There has been a tradition of holding teachers accountable when students are not performing in schools (Gottlieb 2015). As disruptive behaviour negatively affects both classroom climate and academic achievement, one might be led to believe that teachers who are not able to manage this kind of behaviour are failing to facilitate good learning conditions for their students.

An issue with a high degree of disruptive behaviour is that teachers may feel de-skilled (Geddes 2006). As one of their primary objectives is to facilitate learning, teachers might be very qualified for doing so and possess great skills in how they teach their subjects. What they do not seem to have, however, is sufficient skill in managing disruptive behaviour. The documents on 'Knowledge Promotion' in Norway and 'Every Student Succeeds Act' in United States barely mention the issue of disruptive behaviour (Ministry of Education and Research 2006; U.S Department of Education 2015). As a consequence, teachers might be insufficiently educated in skills needed to establish a positive classroom climate and to manage disruptive behaviour. If this is the case, one could claim that the rules and maxims learned at the beginner-level of Dreyfus' Skill-Model are not sufficiently developed, which in turn might make it easier for teachers to place the responsibility of lacking abilities to establish a positive classroom climate on their not having been properly introduced to the skills they need to do so. Gottlieb (2015) might support this by saying that student-teachers ${ }^{4}$ often are instructed to do tasks like observing classes and meetings and assist with grading. These student-teachers seem to serve mainly as observers, and not active participants. The issue advanced here is that such practice does not provide student-teachers with insight into the flexible nature of the teaching profession and responsibility for outcomes of situations that they are emotionally involved in and that matter to them. 
Another perspective on the results illustrated in Table 5 is that teachers have some positive influence on disruptive behaviour and still possess some authority in the classroom. As teachers seem to possess some authority in the classroom, they have a foundation for further nurturing cooperation with students on establishing a classroom-climate promoting academic and social growth. The key here could be for the teacher to nurture students' emotional involvement for school-related work and strive towards making students perceive that teachers matter to them as teachers are one of the most significant and influential agents in students' lives (Galbo 1989).

\section{Limitations}

Further contextual aspects are lacking in the study. Notable differences we observed during the data collection were that the US schools were (a) more diverse and (b) goals and measurable outcomes of academic achievement were more salient to American students than Norwegian students. In Norway, the goals of each lesson seemed more implicit and students did not have the opportunity to continuously know how they were doing in certain subjects. To get further indications on how these factors may relate to disruptive behaviour, we need more data from these domains. Unfortunately, we did not have the opportunity to collect such data due to a lack of time and resources.

\section{Conclusion}

As a conclusion to this article, we wish to address the issue of the high frequency of disruptive behaviour and students' seemingly low belief in their own influence on disruptive behaviour. We raise the question if this could be explained by our schools becoming fragmented and lacking a sense of emotional involvement in school-related activities. Bakken (2016) documents that $34 \%$ of students aged 15-18 say they feel some degree of 
dissatisfaction in school. This could be linked to disruptive behaviour. Putnam (2000) describes how modern human beings experience loneliness and social isolation. He describes our civil world as an increasingly lacking arena for social communities. Without sense of belonging to a community, there is a sense of emptiness (Bauman 2008). American and Norwegian societies are greatly diverse with variation in students' socio-economic points of departure. School classes may be the only social arena many of the students' experience. If school classes are the only social arena experience by students, promotion of social and emotional growth should be of equal value to academic achievement.

\section{Notes}

${ }^{1}$ The research group contains scholars from Norway and the US, within the disciplines of education, special needs education, sociology, psychology and philosophy.

${ }^{2}$ These findings are presented in an earlier article from our study. The article is currently under review.

${ }^{3}$ In relation to this, we wish to point out that our research is on adolescents between the ages 15-17. We realize that younger students might not be capable of making equally conscious decisions. Our argument is not universal, but directed towards the students in our sample.

${ }^{4}$ The term 'student-teachers' refer to students undergoing education to become teachers.

\section{References}

Bakken, A. 2016. Ungdata. Nasjonale Resultater 2016. NOVA Rapport 8/16. Oslo: NOVA.

Bauman, Z. 2008. Community: Seeking Safety in an Insecure World. Cambridge: Polity Press.

Bauman, Z., and R. Mazzeo. 2012. On Eduation: Conversations with Ricardo Mazzeo. Cambridge: Polity Press. 
Befring, E., and L. Duesund. 2012. "Relasjonsvansker: Psykososial Problematferd.” In Spesialpedagogikk, edited by E. Befring and T. Reidun. Oslo: Gyldendal akademisk.

Benner, P. 2004. "Using the Dreyfus Model of Skill Acquisition to Describe and Interpret Skill Acquisition and Clinical Judgment in Nursing Practice and Education.” Bulletin of Science, Technology \& Society 24 (3): 188-199. doi:10.1177/ 0270467604265061.

Clunies-Ross, P., E. Little, and M. Kienhuis. 2008. "Self-Reported and Actual Use of Proactive and Reactive Classroom Management Strategies and Their Relationship with Teacher Stress and Student Behaviour.” Educational Psychology 28 (6): 693-710. doi:10.1080/01443410802206700.

Colvin, G. 2010. Defusing Disruptive Behavior in the Classroom. Thousand Oaks: Corwin Press.

Dreyfus, H.L. 2004a. "What Could Be More Intelligible than Everyday Intelligibility? Reinterpreting Divison I of Being and Time in the Light of Division II.” Bulletin of Science, Technology and Society 24 (3): 265-274. doi:10.1177/ 0270467604264993.

Dreyfus, H.L. 2014. “Overcoming the Myth of the Mental: How Philosophers Can Benefit from the Phenomenology of Everyday Expertise (2005).” In Skillful Coping: Essays on the Phenomenology of Everyday Perception and Action, edited by M.A. Wrathall. Oxford: Oxford University Press.

Dreyfus, H.L., and S.E. Dreyfus. 1986. Mind over Machine: The Power of Human Intuition and Expertise in the Era of the Computer. New York: Free Press.

Dreyfus, H.L., and S.E. Dreyfus. 2014. "What Is Moral Maturity? Towards a Phenomenology of Ethical Expertise (1992).” In Skillful Coping: Essays on the Phenomenology of 
Everyday Perception, edited by H.L. Dreyfus and M.A. Wrathall. Oxford: Oxford University Press.

Dreyfus, H.L., and M.A. Wrathall. 2007. "Martin Heidegger: An Introduction to His Thought, Work and Life.” In A Companion to Heidegger, edited by H.L. Dreyfus and M. Wrathall. Malden: Blackwell Publishing.

Dreyfus, H.L., and M.A. Wrathall. 2014. Skillful Coping: Essays on the Phenomenology of Everyday Perception and Action. Oxford: Oxford University Press.

Dreyfus, S.E. 2004b. "The Five-Stage Model of Adult Skill Acquisition.” Bulletin of Science, Technology \& Society 24: 177. doi:10.1177/0270467604264992.

Duesund, L. 2014. “Uro I Skolen.” In Pedagogikk - En Grunnbok, edited by H. Stray Janicke and L. Wittek. 568-583. Oslo: Cappelen Damm Akademisk.

Duesund, L., and E. Jespersen. 2004. "Skill Acquisition in Ski Instruction and the Skill Model's Application to Treating Anorexia Nervosa.” Bulletin of Science, Technology \& Society 24 (3): 225-233. doi:10.1177/0270467604265011.

Evertson, C.M., and C.S. Weinstein. 2006. “Classroom Management as a Field of Inquiry.” In Handbook of Classroom Management: Research, Practice and Contemporary Issues, edited by C.M. Evertson and C.S. Weinstein. Mahwah, NJ: Lawrence Erlbaum Associates.

Filsecker, M., and D.T. Hickey. 2014. “A Multilevel Analysis of the Effects of External Rewards on Elementary Students' Motivation, Engagement and Learning in an Educational Game.” Computers \& Education 75: 136-148. doi:10.1016/j. compedu.2014.02.008. 
Fossum, V.M. 2011. "Disorder in schools: a case study based on the observations of one student with disruptive behavior in school (master's thesis)." University of Oslo.

Fowler, Floyd J Jr. 2013. Survey Research Methods. Thousand Oaks: Sage publications.

Galbo, J. 1989. “The Teacher as Significant Adult: A Review of the Literature.” Adolescence 24 (95): 549.

Geddes, H. 2006. Attachment in the Classroom: The Links between Children's Early Experience, Emotional Well-Being and Performance in School. London: Worth Publishing .

Gottlieb, D. 2015. Education Reform and the Concept of Good Teaching (Routledge International Studies in the Philosophy of Education). New York: Taylor \& Francis.

Greene, R.W. 2014. Lost at School. Why Our Kids with Behavioral Challenges are Falling through the Cracks and How We Can Help Them. New York: Scribner.

Honkasilta, J., S. Vehmas, and T. Vehkakoski. 2016. "Self-Pathologizing, Self-Condemning, Self-Liberating: Youths’ Accounts of Their ADHD-related Behavior.” Social Science \& Medicine 150: 248-255. doi:10.1016/j. socscimed.2015.12.030.

Jacobsen, D.I., and J. Thorsvik. 1997. Hvordan Organisasjoner Fungerer. Bergen: Fagbokforlaget.

Johnson, B., and L. Christensen. 2014. Educational Research: Quantitative, Qualitative, and Mixed Approaches. Thousand Oaks: Sage.

Kauffman, J.M., M.P. Mostert, S.C. Trent, and P.L. Pullen. 2010. Managing Classroom Behavior: A Reflective Cased-Based Approach (5th Ed). Boston: Pearson. 
König, J., and C. Kramer. 2016. “Teacher Professional Knowledge and Classroom Management: On the Relation of General Pedagogical Knowledge (GPK) and Classroom Management Expertise (CME).” ZDM : The International Journal on Mathematics Education 48 (1): 139-151. doi:10.1007/s11858-015-0705-4.

Leflot, G., P. Lier, P. Onghena, and H. Colpin. 2010. "The Role of Teacher Behavior Management in the Development of Disruptive Behaviors: An Intervention Study with the Good Behavior Game.” An Official Publication of the International Society for Research in Child and Adolescent Psychopathology 38 (6): 869-882. doi:10.1007/s10802- 010-9411-4.

Levin, J., and J.F. Nolan. 2010. Principles of Classroom Management: A Professional Decision-Making Model. Boston: Pearson.

Ministry of Education and Research. 2006. Knowledge Promotion. Oslo: Ministry of Education and Research. Ministry of Education and Research. 2008. Kvalitet i Skolen (St.Meld. Nr. 31 2007-2008). Oslo: Ministry of Education and Research.

Murphy, J.J. 2013. Conducting Student-Driven Interviews: Practical Strategies for Increasing Student Involvement and Addressing Behavior Problems, School-Based Practice in Action Series. New York: Routledge.

Nash, P., A. Schlösser, and T. Scarr. 2016. “Teachers' Perceptions of Disruptive Behaviour in Schools: A Psychological Perspective.” Emotional and Behavioural Difficulties 21 (2): 167-180. doi:10.1080/13632752.2015.1054670.

Nucci, L., and E. Turiel. 2009. "Capturing the Complexity of Moral Development and Education.” Mind, Brain, and Education 3 (3): 151-159. doi:10.1111/j.1751228X.2009.01065.X. 
Ødegård, M. 2011. “Disorder in schools: Dasein \& absorbed coping (master's thesis).” University of Oslo.

Ødegård, M. 2014. “Uro i Skolen Og Den Menneskelige Væremåte.” Norsk Pedagogisk Tidsskrift. 98 (3): 203-212.

Overland, T. 2007. Skolen og De Utfordrende Elevene: Om Forebygging Og Reduksjon Av Problematferd. Bergen: Fagbokforlaget.

Payne, R. 2015. 'Using Rewards and Sanctions in the Classroom: Pupils' Perceptions of Their Own Responses to Current Behaviour Management Strategies.” Educational Review 67 (4): 483-504. doi:10.1080/ 00131911.2015.1008407.

Pintrich, P.R., and D.H. Schunk. 2002. Motivation in Education: Theory, Research, and Applications. 2nd ed. Upper Saddle River, N.J: Merrill Prentice Hall.

Postholm, M.B. 2013. “Classroom Management: What Does Research Tell Us?” European Educational Research Journal 12 (3): 389-402. doi:10.2304/eerj.2013.12.3.389.

Putnam, R.D. 2000. Bowling Alone: The Collapse and Revival of American Community. New York: Simon \& Schuster.

Ratcliff, N., C.R. Jones, R.H. Costner, E. Savage-Davis, and G.H. Hunt. 2010. “The Elephant in the Classroom: The Impact of Misbehavior on Classroom Climate.” Education 131 (2): 306-314.

Simonsen, B., S. Fairbanks, A. Briesch, D. Myers, and D. Sugai. 2008. "Evidence-Based Practices in Classroom Management: Considerations for Research to Practice.” Education and Treatment of Children 31 (3): 351-380.

Solberg, S. 2013. "Disruptive behavior in school: Wired up - the relationship between disruptive behavior and new technology (master's thesis)." University of Oslo. 
Stavnes, R.L. 2013. "Disruptive behavior in school: Disruptive behavior as physical movements (master's thesis)." University of Oslo.

U.S Department of Education. 2015. Every Student Suceeds Act (ESSA). Washington: U.S Department of Education.

Valseth, M. 2013. "Uro i skolen: Uro og symbolsk interaksjonisme (master's thesis)." University of Oslo.

Woltering, S., and S. Qinxin. 2016. "On the Neuroscience of Self-Regulation in Children with Disruptive Behavior Problems: Implications for Education.” Review of Educational Research 86 (4): 1085-1110. doi:10.3102/ 0034654316673722 